\title{
Towards an integrated in vitro strategy for repeated dose toxicity testing
}

\author{
Tamara Vanhaecke $\cdot$ Marleen Pauwels • \\ Mathieu Vinken · Liesbeth Ceelen • \\ Vera Rogiers
}

Received: 8 April 2011/Accepted: 12 April 2011/Published online: 22 April 2011

(C) Springer-Verlag 2011

Currently, there is clear political incentive in the EU to minimize the number of animals involved in the chemical risk assessment process, particularly holding true for the cosmetics sector. Stringent requirements of full replacement of animals in safety testing are laid down in the EU Cosmetics Directive 76/768/EEC by the implementation of the 7th Amendment (2003/15/EC), setting a rigid time frame for the availability of valid 3R-alternative methods for the safety testing of cosmetic products and their ingredients (EU 2003). An important step forward to achieve this goal has recently been made through a joint initiative by DG Research and Colipa (The European Cosmetics Association). A cluster of calls was launched under the FP7 health programme specifically addressing the replacement of repeated dose systemic toxicity testing in human safety assessment. As such, 6 large-scale collaborative research projects started from January 2011 onwards, covering key themes related to human stem cell technology (SCREENTOX), organ-simulating devices (HeMiBio), human-relevant biomarker detection (DETECTIVE), computational modelling (COSMOS), systems biology (NOTOX) and

\footnotetext{
T. Vanhaecke $(\bowtie) \cdot$ M. Pauwels · M. Vinken · L. Ceelen ·

V. Rogiers

Department of Toxicology, Vrije Universiteit Brussel, Laarbeeklaan 103, 1090 Brussels, Belgium

e-mail: tamara.vanhaecke@vub.ac.be

M. Pauwels

e-mail: mnpauwel@vub.ac.be

M. Vinken

e-mail: mvinken@vub.ac.be

L. Ceelen

e-mail: 1ceelen@vub.ac.be

V. Rogiers

e-mail: vrogiers@vub.ac.be
}

integrated data analysis (TOXBANK). An umbrella coordination and support action project $(\mathrm{COACH})$ is responsible for monitoring progress and potential gaps occurring throughout the 5-year running period. A major task, however, will be to streamline and combine the outcomes of the different projects in order to establish a realistic in vitro strategy to assess repeated dose toxicity.

As in all projects the liver is involved as target organ, one might expect that hepatotoxicity could be used as a test case. This would be of particular interest since it is the major type of toxicity observed during in vivo repeated dose toxicity testing for cosmetic ingredients (Pauwels et al. 2009) and pharmaceutical compounds (Russmann et al. 2009).

Figure 1 demonstrates how such an in vitro testing strategy could look, taking into consideration, the current approach of quantitative risk assessment for cosmetic ingredients using data derived from animal studies. Thus, a margin of safety (MoS) of at least 100 is applied for intraspecies and interspecies variation using the following equation:

$\operatorname{MoS}=\frac{\text { NOAEL }(\text { no observable adverse effect level) }}{\text { systematic exposure dosage }} \geq 100$

In the proposed strategy, a computed NOAEL value, preferably derived from human data $\left(\mathrm{hNOAEL}_{\mathrm{c}}\right)$, could be used for the compound of interest. This estimated in vivo dosage could be obtained via processing of the compound concentration (hNOAEC) that does not cause any adverse effect using an in vitro model. For that purpose, physiologically based pharmacokinetic (PBPK) computational modelling can be applied taking into account an appropriate uncertainty factor for the in vitro/in vivo extrapolation. The hNOAEC value of the compound of interest could, for example, 


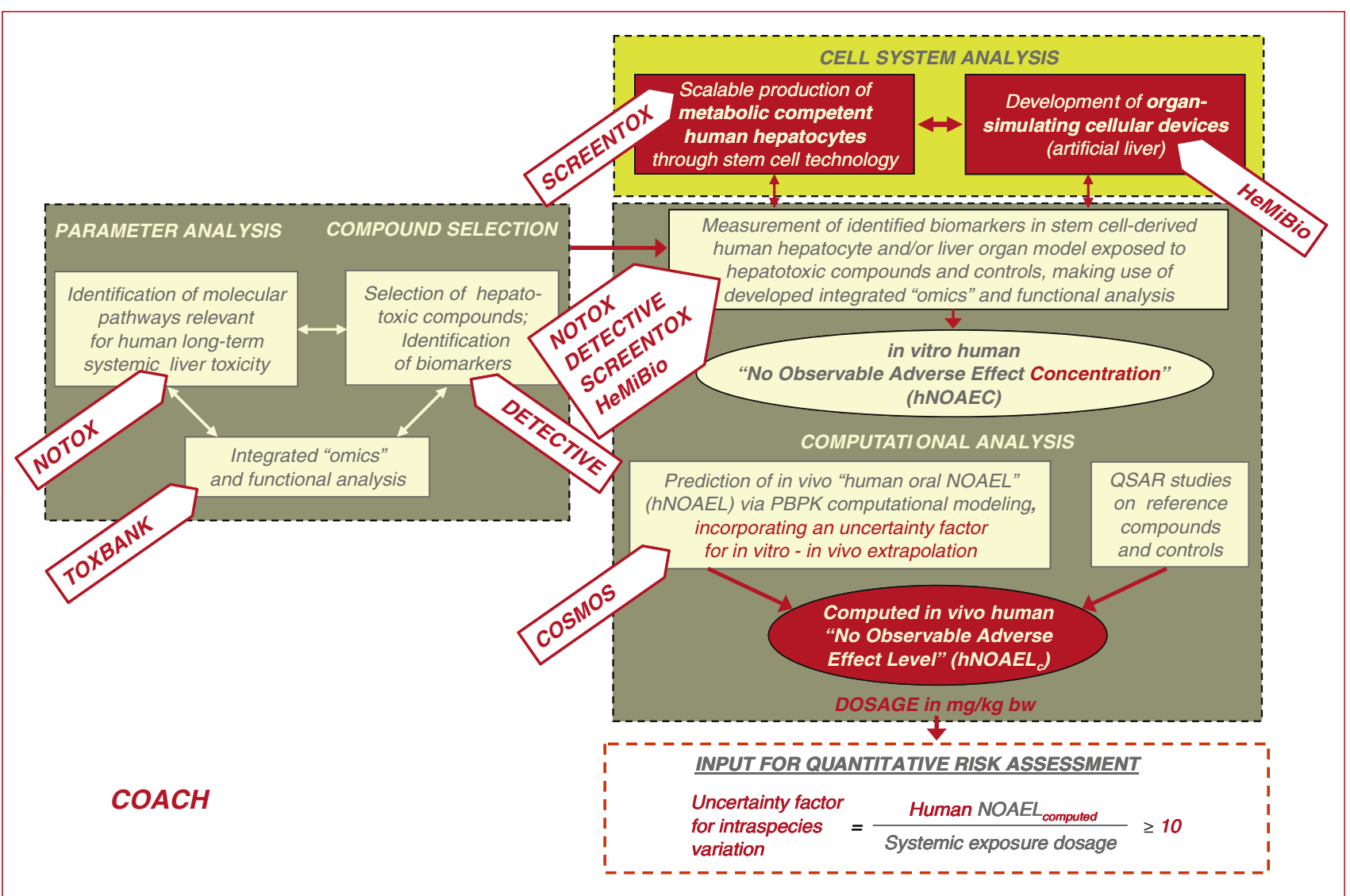

Fig. 1 Proposal for an integrated approach for the in vitro assessment of repeated dose hepatotoxicity. The contributions of the different partners involved in the ongoing EU-Colipa initiative are indicated. (hNOAEC human no observable adverse effect concentration,
hNOAEL human oral NOAEL, $h N O A E L_{C}$ computed hNOAEL, NOAEL no observable adverse effect level, QSAR quantitative structure-activity relationship)

substances. Anyhow, attempts to develop an in vitro alternative to repeated dose toxicity testing in animals is a crucial step forward towards a more animal-friendly way of protecting human health.

\section{References}

EU (2003) Directive 2003/15/EC of the European Parliament and of the Council of 27 February 2003 amending Council Directive 76/768/EEC on the approximation of the laws of the Member States relating to cosmetic products. 2003/15/EC: EU, 2003. OJ L066, 11 March 2003, pp 26-35

Pauwels M, Dejaegher B, Heyden YV, Rogiers V (2009) Critical analysis of the SCCNFP/SCCP safety assessment of cosmetic ingredients (2000-2006). Food Chem Toxicol 47(4):898-905

Russmann S, Kullak-Ublick GA, Grattagliano I (2009) Current concepts of mechanisms in drug-induced hepatotoxicity. Curr Med Chem 16:3041-3053 